\title{
ARTICLE \\ Veratridine modifies the gating of human voltage-gated sodium channel Nav1.7
}

\author{
Xiao-yu Zhang ${ }^{1}$, Rui-yun $\mathrm{Bi}^{2}$, Peng Zhang ${ }^{1}$ and Ye-hua Gan ${ }^{1}$
}

\begin{abstract}
Veratridine is a lipid-soluble neurotoxin derived from plants in the family Liliaceae. It has been broadly investigated for its action as a sodium channel agonist. However, the effects of veratridine on subtypes of sodium channels, especially Nav1.7, remain to be studied. Here, we investigated the effects of veratridine on human Nav1.7 ectopically expressed in HEK293A cells and recorded Nav1.7 currents from the cells using whole-cell patch clamp technique. We found that veratridine exerted a dose-dependent inhibitory effect on the peak current of Nav1.7, with the half-maximal inhibition concentration $\left(\mathrm{IC}_{50}\right)$ of $18.39 \mu \mathrm{M}$. Meanwhile, veratridine also elicited tail current (linearly) and sustained current [half-maximal concentration (EC $\left.C_{50}\right): 9.53 \mu \mathrm{M}$ ], also in a dosedependent manner. Veratridine $(75 \mu \mathrm{M})$ shifted the half-maximal activation voltage of the Nav1.7 activation curve in the hyperpolarized direction, from $-21.64 \pm 0.75 \mathrm{mV}$ to $-28.14 \pm 0.66 \mathrm{mV}$, and shifted the half-inactivation voltage of the steady-state inactivation curve from $-59.39 \pm 0.39 \mathrm{mV}$ to $-73.78 \pm 0.5 \mathrm{mV}$. An increased frequency of stimulation decreased the peak and tail currents of Nav1.7 for each pulse along with pulse number, and increased the accumulated tail current at the end of train stimulation. These findings reveal the different modulatory effects of veratridine on the Nav1.7 peak current and tail current.
\end{abstract}

Keywords: veratridine; Nav1.7; channel activation; channel inactivation; electrophysiology; HEK293 cells

Acta Pharmacologica Sinica (2018) 39:1716-1724; https://doi.org/10.1038/s41401-018-0065-z

\section{INTRODUCTION}

The alkaloid neurotoxin veratridine is found in the rootstock of hellebore and the seeds of sabadilla [1] and is widely used as a sodium channel opener to increase sodium ion $\left(\mathrm{Na}^{+}\right)$accumulation inside the cells, which can be detected through radioactive sodium ion flux assays [2, 3] or voltage-sensitive dye [4, 5]. Veratridine elicits membrane depolarization in lymphatic vessels and enhances contraction both in lymphatic vessels [6] and in smooth muscle myocytes [7, 8]; it also prolongs the action potential in ventricular cardiomyocytes, leading to early afterdepolarization and reflection [9]; increases sperm motility [10]; and causes catecholamine secretion [2]. Veratridine has the same pharmacological effect as aconitine, grayanotoxin and batrachotoxin (BTX), which can compete with it for binding site [11-14]. Meanwhile, tetrodotoxin (TTX) has a different binding site on sodium channels and can inhibit veratridine-induced sodium channel activation $[15,16]$.

Voltage-gated sodium channels (VGSCs) are activated by depolarization, with the $\mathrm{S} 4$ segment in the a subunit serving as the voltage sensor; the channels are inactivated during the ongoing depolarization with a fast and a slow component, the former of which is mediated by the inactivation gate [13, 17-19], and they will later be deactivated when the channel returns to its resting membrane potential (during the tail current) [20, 21]. VGSCs are classified into nine subtypes, from Nav1.1 to Nav1.9, and have different expression profiles in different tissues [19, 22]. A VGSC is composed of two types of subunits: a pore-forming a subunit and one or two associated $\beta$ subunits [23]. According to their sensitivity to TTX, VGSCs can be divided into two subgroups, namely, the TXX-sensitive group and the TX-resistant group. Nav1.5, Nav1.8, and Nav1.9 are TTX resistant, while the other subtypes are TTX sensitive [24].

Nav1.7 plays important roles in sensory and sense-driven functions such as pain, cough, olfactory reflexes, and acid sensation, which make it an important drug target $[25,26]$, and this channel is expressed abundantly in peripheral sensory neurons such as dorsal root ganglion (DRG) neurons, where it regulates cell excitability by modulating the neuronal action potential threshold $[19,22,25]$. In DRG neurons, veratridine inhibits sodium channel conductance in a dose-dependent manner, exerts different modulatory effects on the voltage gating of TTX-sensitive and TTX-resistant channels [27], and induces different $\mathrm{Ca}^{2+}$ responses [28]. The modulatory effect of veratridine on the characteristics of sodium channels has been reported mostly for skeletal muscle Nav1.4 [12, 29] and murine vas deferens myocyte Nav1.6 [11,30], while little is known about its effect on neuronal Nav1.7 [11]; in particular, its effect on the gating properties of Nav1.7 is largely unknown. Therefore, in this study, we investigated the effect of veratridine on the voltagedependent sodium channel Nav1.7.

\section{MATERIALS AND METHODS}

Ectopic expression of human Nav1.7 in human embryonic kidney cell line 293A cells

Human embryonic kidney cell line 293A (HEK293A) cells were cultured in Dulbecco's modified Eagle's medium (Gibco, Grand Island, NY, USA) supplemented with $10 \%$ fetal bovine serum

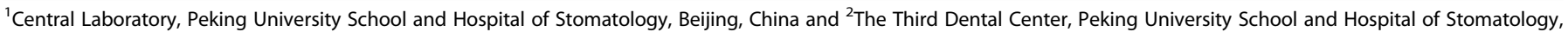
Beijing 100081, China

Correspondence: Ye-hua Gan (kqyehuagan@bjmu.edu.cn)

Received: 8 November 2017 Accepted: 5 June 2018

Published online: 27 June 2018 
(Gibco, Grand Island, NY, USA) at $37^{\circ} \mathrm{C}$ in an atmosphere with $5 \%$ $\mathrm{CO}_{2}$. The cells were cotransfected with one plasmid containing SCN9A (human Nav1.7 a subunit) plus DsRed2 and another one containing SCN1B/SCN2B (human VGSC $\beta 1$ and $\beta 2$ subunits) plus EGFP [31] using VigoFect Reagent (Vigorous Biotechnology, Beijing, China) according to the manuals, as described previously [32]. After 2 days of transfection, cells were trypsinized and plated on poly-lysine-coated coverslips $1-3 \mathrm{~h}$ before electrophysiological recording. Experiments were performed on cells positive for DsRed 2 and EGFP, detected at $550 \mathrm{~nm}$ and $488 \mathrm{~nm}$ with an Olympus IX70 microscope. Fluorescent images were captured with a Zeiss 700 upright confocal microscope.

Electrophysiology

Whole-cell patch-clamp recordings were performed using an EPC/ 10 amplifier (HEKA Elektronic, Lambrecht/Pfalz, Germany) and

a
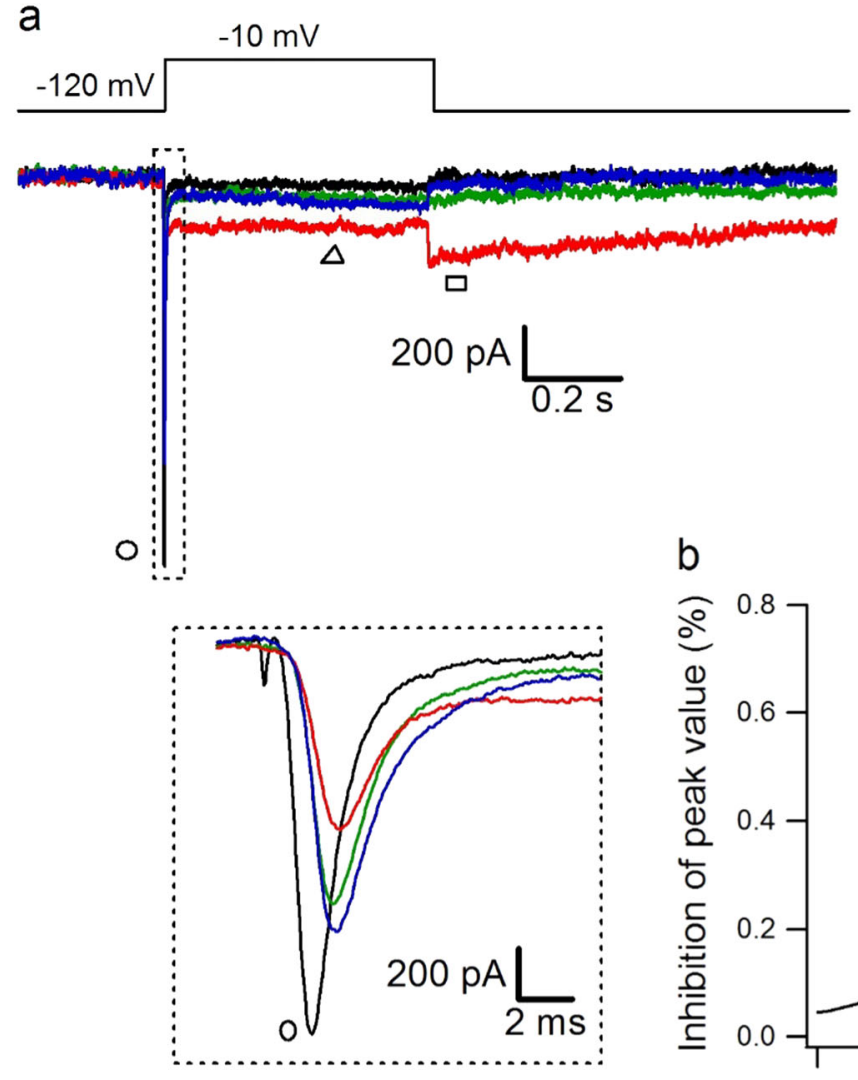

b
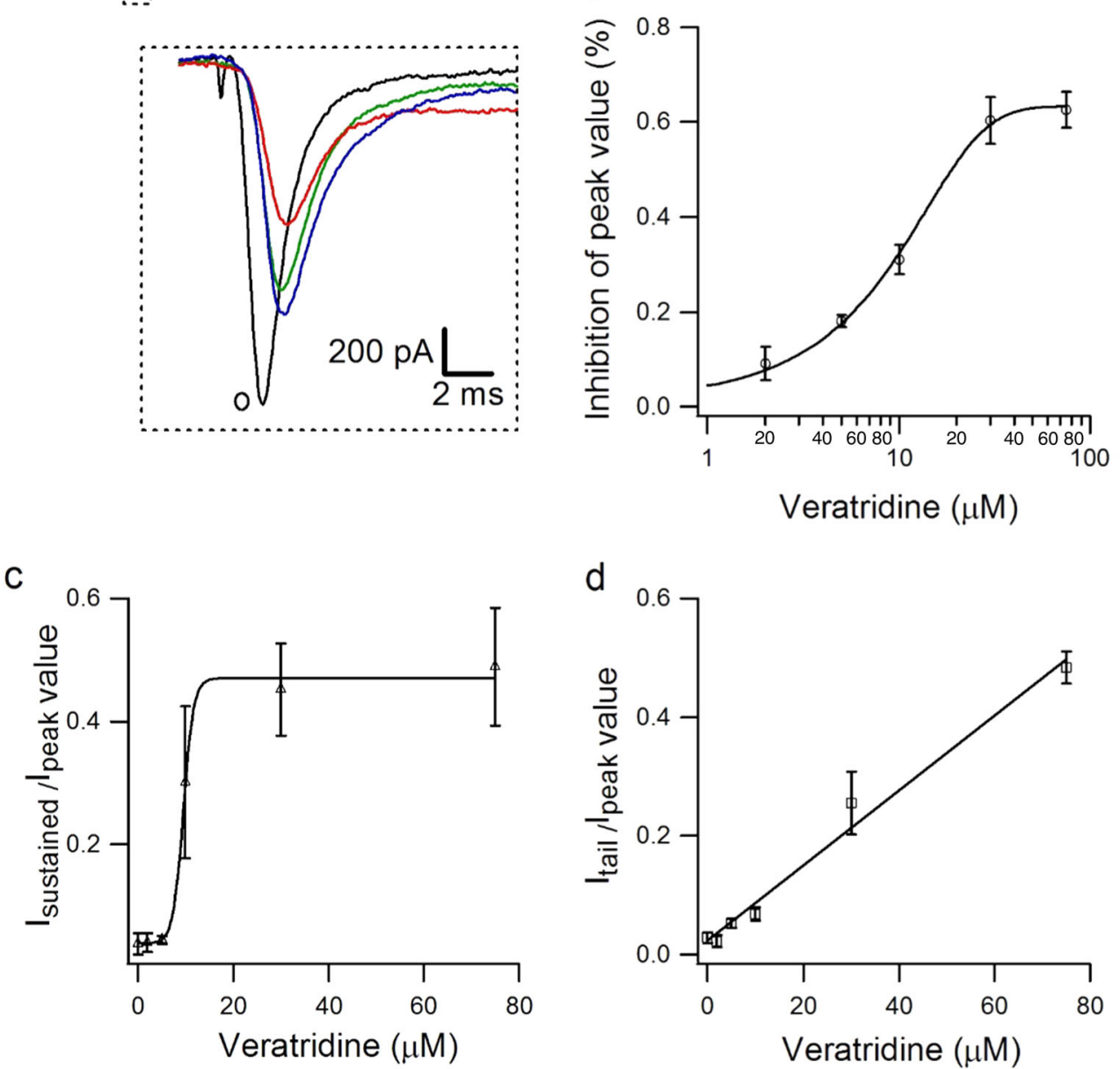

Fig. 1 Dose-dependent effect of veratridine on Nav1.7 currents. a Typical traces showing the effect of veratridine (10 $\mu \mathrm{M}$ and $75 \mu \mathrm{M})$ on Nav1.7 peak current, sustained current, and tail current compared with the control condition (without veratridine) in the same cell, which was activated with $500 \mathrm{~ms}$ voltage steps between -80 and $+20 \mathrm{mV}$ in $5 \mathrm{mV}$ increments from a holding potential of $-100 \mathrm{mV}$ at $\sim 0.2 \mathrm{~Hz}$. b-d Dose-dependent inhibitory effects of veratridine at $2-75 \mu \mathrm{M}(n=3$ for each concentration) on the peak current (b), relative sustained current (c), and relative tail current (d) of Nav1.7; these values were normalized to the corresponding values from before veratridine and fitted with the equation $y=$ base $+\max /\left[1+\exp \left(x_{\text {half }}-x\right) k\right]$, where $y$ is the Nav1.7 peak current, $x_{\text {half }}$ is the $I_{50}$ of veratridine, $k$ is slope factor, and base and max are the minimum and maximum values of $y$ 
Pulse Software (HEKA Elektronic, Lambrecht/Pfalz, Germany) at room temperature as previously described with a slight modification [33]. Cells were bathed in an extracellular solution composed of the following (in $\mathrm{mM}$ ): $150 \mathrm{NaCl}, 5 \mathrm{KCl}, 10 \mathrm{HEPES}, 2.5 \mathrm{CaCl}_{2}$, and 1 glucose ( $\mathrm{pH}$ adjusted to 7.4 with $\mathrm{NaOH}$ ). Patch pipettes were fabricated using a P-97 puller (Narishige, Tokyo, Japan) to achieve resistances of 2-3M $\mathrm{M} \Omega$ when filled with the intracellular solution, which was composed of the following (in $\mathrm{mM}$ ): $107 \mathrm{CsF}, 10 \mathrm{NaCl}, 2$ $\mathrm{MgCl}_{2}, 1 \mathrm{CaCl}_{2}, 10$ HEPES, 10 EGTA, and $10 \mathrm{TEACl}$ (pH adjusted to 7.2 with $\mathrm{CsOH}$ ). Currents were filtered at $2.9 \mathrm{kHz}$ and digitized at $10 \mathrm{kHz}$. Serious resistance was compensated by $70-80 \%$ during the whole-cell recording. TTX was stocked as $1 \mathrm{mM}$ in water and diluted to $0.5 \mu \mathrm{M}$ with the extracellular solution when used, and veratridine was stocked as $75 \mathrm{mM}$ in ethanol and diluted to 1-75 $\mu \mathrm{M}$ with extracellular solution when used. All drugs were from Sigma unless indicated otherwise.

Voltage protocols

Cells were depolarized from a holding potential $(-100 \mathrm{mV})$ to test potentials between -80 and $+50 \mathrm{mV}$ (at $5 \mathrm{mV}$ increments) for 50 $\mathrm{ms}$ at $1 \mathrm{~Hz}$ to obtain a current-voltage $(I-V)$ curve and a steadystate activation curve. To obtain a steady-state inactivation curve, we held the cells at a given membrane potential for $500 \mathrm{~ms}$ from holding potentials from -120 to $0 \mathrm{mV}$ (at $5 \mathrm{mV}$ increments) before a depolarization to $-10 \mathrm{mV}$ for $50 \mathrm{~ms}$. Activation and inactivation curves were fitted to a Boltzmann function of the form: $I / I_{\max }$ (or $\left.G / G_{\max }\right)=\left\{1+\exp \left[\left(V_{\mathrm{m}}-V_{1 / 2}\right) / k\right]\right\}^{-1}\left(V_{1 / 2}\right.$, half-maximal activation voltage; $k$, slope factor; and $V_{\mathrm{m}}$, membrane potential).
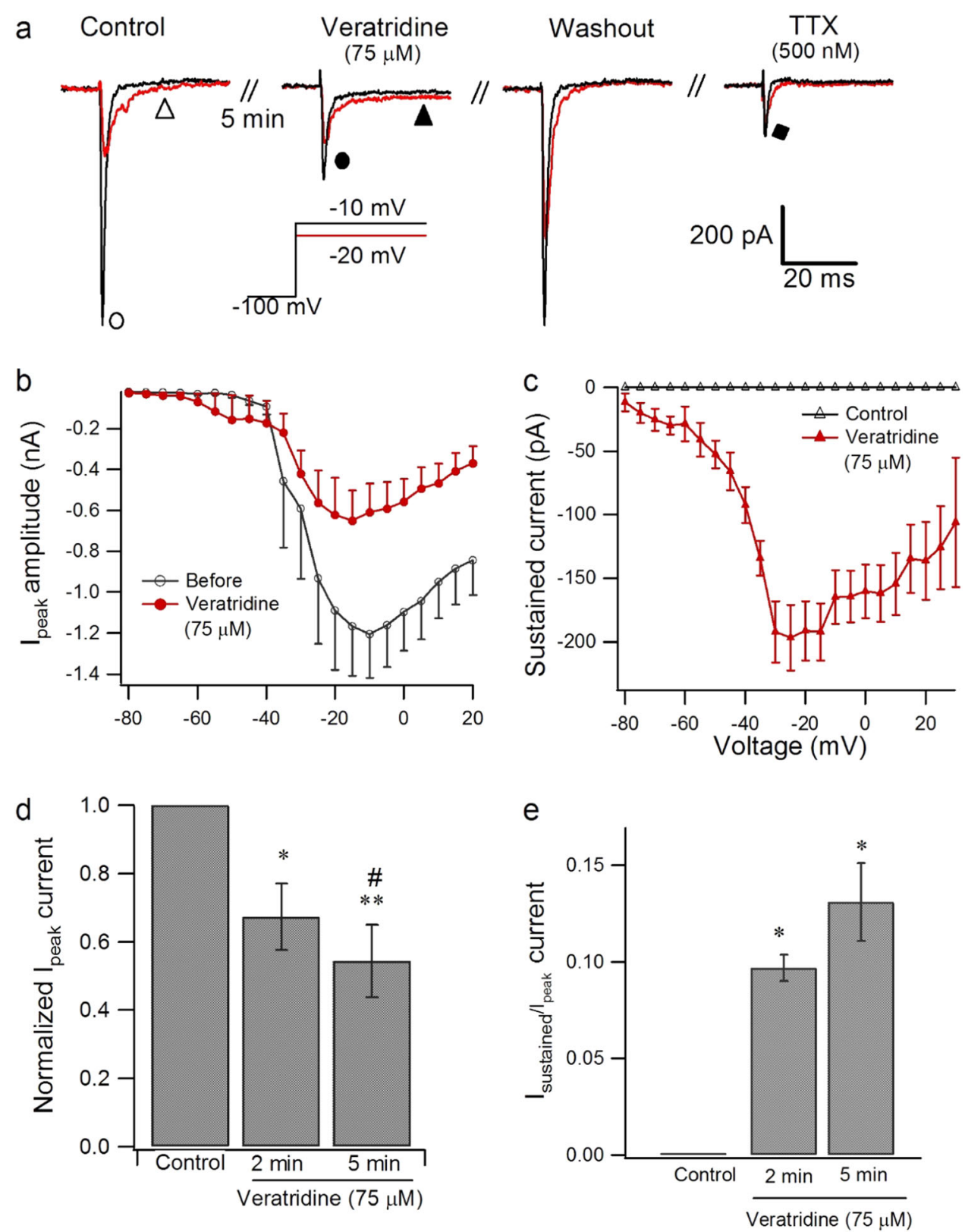

Fig. 2 Effect of veratridine on activation of Nav1.7 currents. a Typical traces of inhibition of the Nav1.7 peak current by $75 \mu \mathrm{M}$ veratridine or $500 \mathrm{nM}$ TTX after application for 3 min extracellularly when evoked from a holding potential of $-100 \mathrm{mV}$ to $50 \mathrm{~ms}$ test pulses between -20 $\mathrm{mV}$ and $-10 \mathrm{mV}$ at $0.5 \mathrm{~Hz}$. b, c Current-voltage relationship of Nav1.7 peak current (b) and sustained current (c) modulated by $75 \mu \mathrm{M}$ veratridine $(n=8)$ compared with control $(n=8)$. d, e Effect of veratridine $(75 \mu \mathrm{M})$ on peak value of $I_{\mathrm{Na}}(\mathbf{d}, n=8)$ and sustained current $(\mathbf{e}, n=$ 4) after application for $2-5$ min. Paired Student's $t$ test, ${ }^{*} P<0.05,{ }^{* *} P<0.01$ vs control, ${ }^{\#} P<0.05$ vs 2 min 
Data analysis

Data were analyzed with the software Igor (Wavemetrics, Lake Oswego, OR, USA) and shown as the mean \pm SEM. Significance was tested using the two-tailed paired or unpaired Student's $t$ test as indicated $\left({ }^{*} P<0.05,{ }^{* *} P<0.01,{ }^{* *} P<0.001\right)$.

\section{RESULTS}

Voltage dependence of Nav1.7 current

Nav1.7 currents were recorded in HEK293A cells transiently coexpressing hNav1.7 sodium channel a subunit and $\beta$ subunits; these cells were indicated by their expression of the fluorescent proteins DsRed2 and EGFP as in Figure S1a. The Nav1.7 channel was activated with a peak amplitude of $194 \pm 37.9 \mathrm{pA} / \mathrm{pF}(n=11$, Figure S1b, S1c), The steady-state activation curve of Nav1.7, fitted by the Boltzmann equation, showed half-maximal activation $\left(V_{1 / 2}\right)$ at $-27.8 \pm 0.01 \mathrm{mV}$ and a slope factor $k=4.15 \pm 0.23 \mathrm{mV}$ (Figure S1d). The inactivation curve, also fitted by the Boltzmann equation, showed $V_{1 / 2}$ at $-66.28 \pm 0.17 \mathrm{mV}$ and $k=5.99 \pm 0.15 \mathrm{mV}$ $(n=11)$ (Figure S1d). In addition, there was little or no detectable sodium current in the nontransfected cells, in contrast to the transfected cells ( $n=7$ for nontransfected cells and $n=8$ for transfected cells, $P<0.05$, Figure S2).

Dose-dependent effect of veratridine on Nav1.7 current

Veratridine is regarded as a sodium channel activator [2-5], but the effects of different doses of veratridine on Nav1.7 current have not been reported. Here, we used veratridine at different doses to examine its effect on peak current, sustained current, and tail current (Fig. 1a). Nav1.7 currents were activated with $500 \mathrm{~ms}$ voltage steps between -80 and $+20 \mathrm{mV}$ at $5 \mathrm{mV}$ increments from a holding potential of $-100 \mathrm{mV}$ at $\sim 0.2 \mathrm{~Hz}$, before and after different doses of veratridine from 2 to $75 \mu \mathrm{M}$. The value of peak currents at different doses were normalized and compared to the peak current before veratridine, showing a dosedependent inhibitory effect of veratridine from 2 to $75 \mu \mathrm{M}$, with the $\mathrm{IC}_{50}$ being $18.39 \mu \mathrm{M}$ (Fig. $1 \mathrm{~b}, n=3$ ). Veratridine at $10 \mu \mathrm{M}$ decreased the peak amplitude of Nav1.7 by $\sim 31 \%(P<0.01, n=5$, Figure S3).

Sustained inward currents were induced by veratridine (2-75 $\mu \mathrm{M})$ during depolarization; these currents increased in a dosedependent manner and were saturated at $30-75 \mu \mathrm{M}$, with $\mathrm{EC}_{50}$ being $9.53 \mu \mathrm{M}$ (Fig. 1c, $n=3$ ). Veratridine $(2-75 \mu \mathrm{M})$ also evoked tail currents during repolarization; these currents were linearly related to the concentration of veratridine (Fig. $1 \mathrm{~d}, n=3$ ), which is consistent with a previous study on skeletal muscle sodium channels [29].
Veratridine affected Nav1.7 activation

To investigate further the effect of veratridine on Nav1.7 currents, we used $75 \mu \mathrm{M}$ as a standard concentration. With extracellular application of veratridine $(75 \mu \mathrm{M})$ for $1-5 \mathrm{~min}$, the amplitude of Nav1.7 currents was reduced as exemplified in Fig. 2a; the change was voltage dependent, with significant inhibition occurring at -10 to $20 \mathrm{mV}$ from a holding potential of $-100 \mathrm{mV}(n=8, P<$ 0.05 , Student's paired $t$ test, Figure S4), and the peak amplitude of Nav1.7 currents was reduced to $54.3 \%$ by veratridine $(n=8, P<$ 0.01 ) (Fig. 2b). Extracellular application of $\Pi \mathrm{TX}$ for $3 \mathrm{~min}$ at $500 \mathrm{nM}$ and $1 \mu \mathrm{M}$ reversibly reduced Nav1.7 currents by $70.36 \%$ and $96.3 \%$, respectively, compared with Nav1.7 currents before drug application $(500 \mathrm{nM}, n=4, P<0.001 ; 1 \mu \mathrm{M}, n=8, P<0.001$, Figure S5).

Veratridine at $75 \mu \mathrm{M}$ induced a voltage-dependent sustained current, which peaked at $-20 \pm 5 \mathrm{mV}$ (Fig. 2c, $n=8$ ), while $\Pi \mathrm{TX}$ did not induce any sustained current or tail current (Fig. 2a, $n=4$; Figure $\mathrm{S} 5, n=8$ ). The inhibitory effect of veratridine on the Nav1.7 peak current was active at $2-5 \mathrm{~min}$, and there was $~ 33 \%$ and $45 \%$ inhibition after 2 and 5 min of application, respectively, compared with the control (Fig. 2d, $n=8, P<0.05$ for 2 min vs. control; $P<$ 0.01 for $5 \mathrm{~min}$ vs. control; $P<0.05$ for $5 \mathrm{~min}$ vs. $2 \mathrm{~min}$ ), while typical sustained currents evoked from $-100 \mathrm{mV}$ to $-25 \mathrm{mV}$ remained stable after 2-5 $\mathrm{min}$ of application (Fig. $2 \mathrm{e}, n=4, P>0.05$ for $2 \mathrm{~min}$ vs. $5 \mathrm{~min}$ ).

In addition to the effect of veratridine on the amplitude of Nav1.7 currents, we found that the activation curve of the Nav1.7 channel showed a leftward shift after treatment with veratridine $(75 \mu \mathrm{M})$, with $V_{1 / 2}$ altered from $-21.64 \pm 0.75 \mathrm{mV}$ to $-28.14 \pm 0.66$ $\mathrm{mV}(n=5, P<0.05$, paired Student's $t$ test), while little change was observed in the slope factor $(k=7.12 \pm 0.67 \mathrm{mV}$ and $7.83 \pm 0.6 \mathrm{mV}$ before and after veratridine, respectively) (Fig. 3a). TTX (500 nM) shifted the $V_{1 / 2}$ of Nav1.7 only slightly and nonsignificantly from $-22.21 \pm 0.59 \mathrm{mV}$ to $-26.78 \pm 1.1 \mathrm{mV} \quad(n=3, P>0.05$, paired Student's $t$ test), and there was little change in the slope factor (Fig. 3b).

Veratridine affected steady-state inactivation of Nav1.7 currents The effect of veratridine $(75 \mu \mathrm{M})$ on steady-state inactivation of Nav1.7 currents was also examined. Cells expressing functional Nav1.7 were excited from a holding potential ranging from -120 $\mathrm{mV}$ to $0 \mathrm{mV}$ for $500 \mathrm{~ms}$ before a test pulse of $-10 \mathrm{mV}$ for $50 \mathrm{~ms}$ (Fig. 4a). There was an inhibitory effect of $75 \mu \mathrm{M}$ veratridine on the peak amplitude of inactivation currents compared with the control, and the inhibition from the holding potential of $-60 \mathrm{mV}$ was more effective than that of $-120 \mathrm{mV}$ (31.6\% inhibition for $-120 \mathrm{mV}, 82.6 \%$ inhibition for $-60 \mathrm{mV}, n=5, P<0.001$, Figure $\mathrm{S} 6$ ).
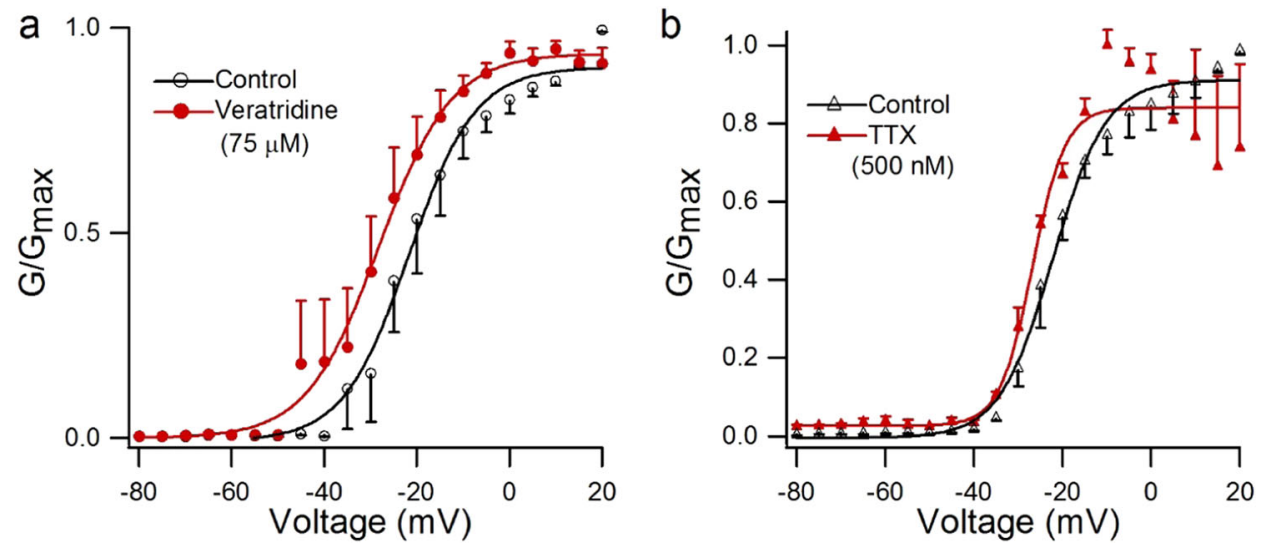

Fig. 3 Steady-state activation curve modified by $500 \mathrm{nM}$ TTX and $75 \mu \mathrm{M}$ veratridine. Steady-state activation curve in the absence and presence of $75 \mu \mathrm{M}$ veratridine $(\mathbf{a}, n=5)$ or $500 \mathrm{nM} \operatorname{TTX}(\mathbf{b}, n=3)$. Cells were excited from a holding potential of $-100 \mathrm{mV}$ to the indicated voltage for $50 \mathrm{~ms}$, and curves were fitted with the Boltzmann equation 


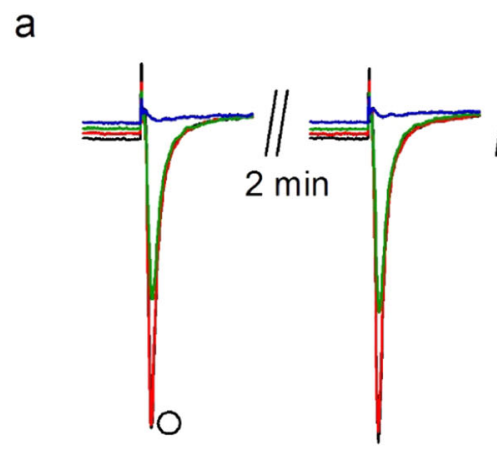

b

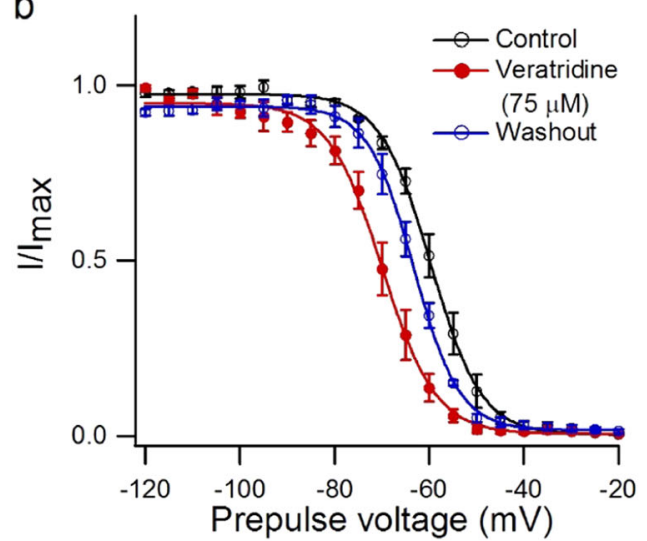

Veratrine $(75 \mu \mathrm{M})$

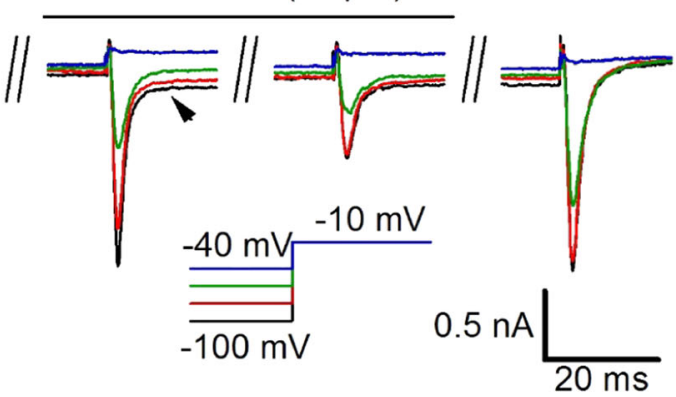

C

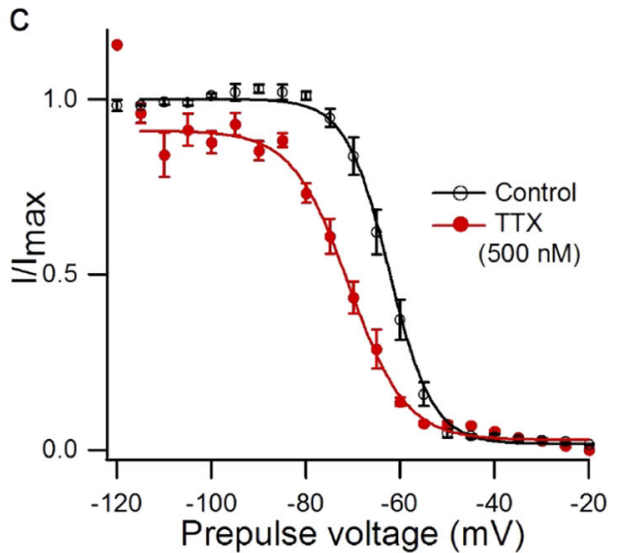

Fig. 4 Effect of veratridine on inactivation of Nav1.7 currents. a Representative steady-state inactivation currents (arrow) and sustained currents (arrowhead) modified by $75 \mu \mathrm{M}$ veratridine when cells were excited from a holding potential of $-100 \mathrm{mV}$ to $-40 \mathrm{mV}$ for $500 \mathrm{~ms}$ followed by a test pulse of $-10 \mathrm{mV}$ for $50 \mathrm{~ms}$. b Steady-state inactivation curve of Nav1.7 currents, excited from a holding potential of $-120 \mathrm{mV}$ to $-20 \mathrm{mV}$ for $500 \mathrm{~ms}$ following a step pulse to $-10 \mathrm{mV}$ for $50 \mathrm{~ms}$, in the presence and absence of $75 \mu \mathrm{M}$ veratridine. Curves were fitted with the Boltzmann equation, where $V_{1 / 2}=-59.66 \pm 0.18 \mathrm{mV}, k=5.34 \pm 0.16 \mathrm{mV}$ for the control; $V_{1 / 2}=-69.91 \pm 0.32 \mathrm{mV}, k=5.63 \pm 0.28 \mathrm{mV}$ after veratridine treatment; and $V_{1 / 2}=-63.26 \pm 0.18 \mathrm{mV}, k=4.81 \pm 0.16 \mathrm{mV}$ for drug washout, $n=5$. c Steady-state inactivation curve of Nav1.7 currents in the presence and absence of $500 \mathrm{nM}$ TTX fitted with the Boltzmann equation, where $V_{1 / 2}=-62.33 \pm 0.17 \mathrm{mV}, k=4.58 \pm 0.15 \mathrm{mV}$ for the control; $V_{1 / 2}=-70.85 \pm 0.59 \mathrm{mV}, k=5.98 \pm 0.52 \mathrm{mV}$ after TTX treatment, $n=3$

TTX $(500 \mathrm{nM})$ showed a similar effect $(68.8 \%$ inhibition for -120 $\mathrm{mV}, 86.3 \%$ inhibition for $-60 \mathrm{mV}, n=3, P<0.01$, Figure S6).

Veratridine shifted the steady-state inactivation curve of Nav1.7 in the hyperpolarized direction, with $V_{1 / 2}$ shifting from $-59.66 \pm$ $0.18 \mathrm{mV}$ to $-69.91 \pm 0.32 \mathrm{mV}$, and after $10 \mathrm{~min}$ for drug washout it returned to $-67.28 \pm 0.22 \mathrm{mV}(n=5, P<0.05$, paired Student's $t$ test), while little change was observed in the slope factor (Fig. 4b). TTX $(500 \mathrm{nM})$ showed a similar effect: the $V_{1 / 2}$ of Nav1.7 altered from $-62.33 \pm 0.17$ to $-70.85 \pm 0.59 \mathrm{mV}(n=3, P<$ 0.001 , paired Student's $t$ test, Fig. 4c), and the slope factor changed from $4.58 \pm 0.15$ to $5.98 \pm 0.52 \mathrm{mV}(n=3, P<0.05$, paired Student's $t$ test, Fig. 4c). Meanwhile, veratridine at $10 \mu \mathrm{M}$ did not shift the activation or inactivation curve of Nav1.7 currents (Figure S7).

Veratridine enhanced the tail current of Nav1.7

When cells were returned to a holding potential of $-100 \mathrm{mV}$ after a step depolarization to $-10 \mathrm{mV}$ for $50 \mathrm{~ms}$ from a conditioning prepulse $(500 \mathrm{~ms})$ ranging from $-100 \mathrm{mV}$ to $40 \mathrm{mV}$, the extracellular application of veratridine $(75 \mu \mathrm{M})$ induced prepulsedependent activation of tail current of Nav1.7 (Fig. 5a). Under normal conditions, the peak value of the tail current was very small, measuring $9 \%$ of the peak current through the inactivated channel, whereas after veratridine the tail current increased to $59 \%(n=5, P<0.01$, paired Student's $t$ test) (Fig. $5 \mathrm{~b})$, which diminished after a washout period of more than $10 \mathrm{~min}$. The parallel inactivation curve of the tail current, fitted with the Boltzmann equation, showed $V_{1 / 2}$ at $-84.61 \pm 1.64 \mathrm{mV}$ and $k=$
$9.42 \pm 1.74 \mathrm{mV}$ (Fig. $5 \mathrm{c})(n=6)$. The channel must open before the tail current can be induced by the veratridine $(75 \mu \mathrm{M})$ during repolarization, as when cells were depolarized from -100 to -10 $\mathrm{mV}$ for different durations from 1 to $60 \mathrm{~ms}$ at $0.1 \mathrm{~Hz}$, the peak current and tail current increased from 1 to $3 \mathrm{~ms}$ and reached their maximum value at $3 \mathrm{~ms}$ duration, remaining unchanged when the duration increased from 3 to $60 \mathrm{~ms}$; the duration at half maximum was $2.46 \mathrm{~ms}$ for the peak current and $2.47 \mathrm{~ms}$ for the tail current (Figure $\mathrm{S} 8, n=3$ ).

Use-dependent modulation of Nav1.7 by veratridine

Nav1.7 currents in response to a train of $5 \mathrm{~ms}$ pulse stimuli from -100 to $-10 \mathrm{mV}$ at $2 \mathrm{~Hz}, 10 \mathrm{~Hz}$, or $40 \mathrm{~Hz}$ for $10 \mathrm{~s}$ were detected after equilibrium of veratridine at $75 \mu \mathrm{M}$ for $\sim 2 \mathrm{~min}$ as in Fig. 6 a. Because each consecutive pulse caused a smaller net increment in the inward current (tail current), there was a nonlinear increase in the inward current after $10 \mathrm{~s}$ of stimulation, especially for a highfrequency stimulus of $40 \mathrm{~Hz}$, at which frequency the current was $\sim 3.5$ times larger than the current at $2 \mathrm{~Hz}$ (Fig. $6 \mathrm{~b}, n=4, P<0.05$ ). The relative increase in inward current evoked by each stimulus decreased with the prolongation of the stimulus and reached a constant value or even vanished after 1-4 s. For single-pulseevoked sodium currents, especially with the first seven pulses, the peak current and tail current both decreased along with the pulse number, especially for a high frequency of $40 \mathrm{~Hz}$, which showed $47 \pm 6 \%$ inhibition of the peak current (Fig. $6 c, n=3, P<0.01$ ) and $43 \pm 7 \%$ inhibition of the tail current (Fig. $6 c, n=3, P<0.05$ ) compared with that at $2 \mathrm{~Hz}$. 
a
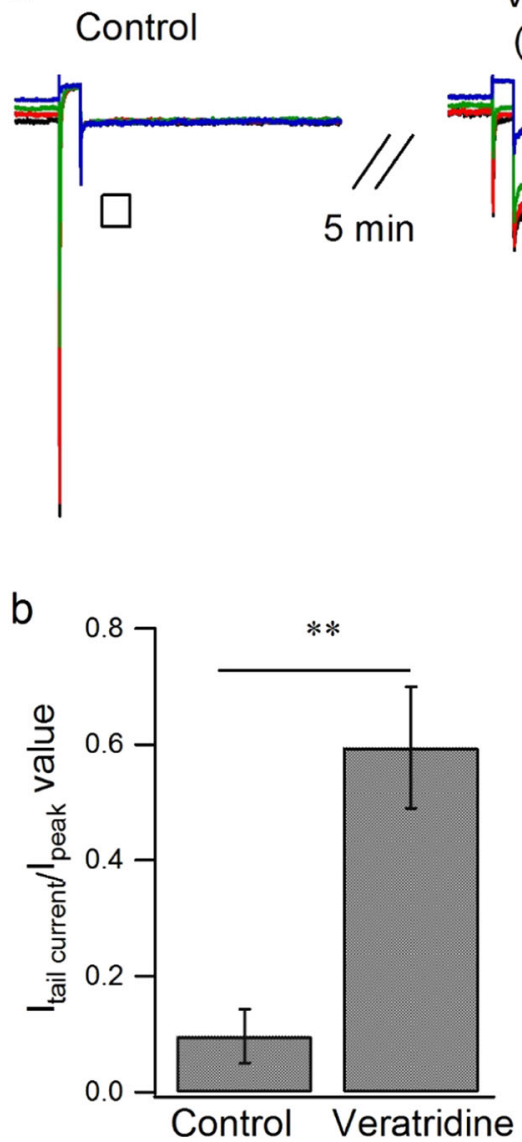

Veratridine $(75 \mu \mathrm{M})$
Washout

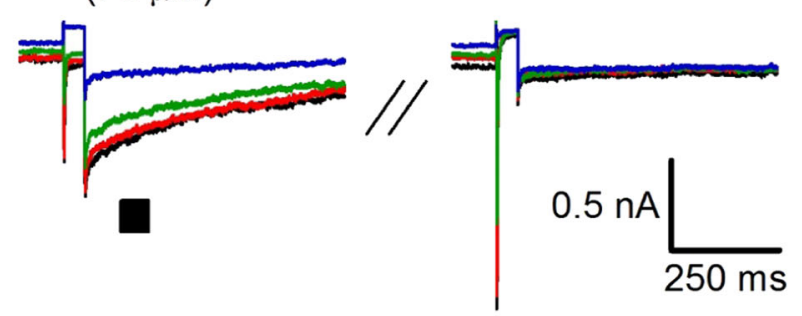

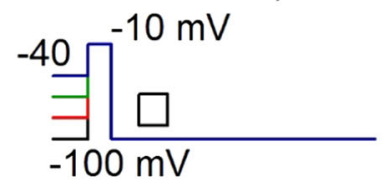

C

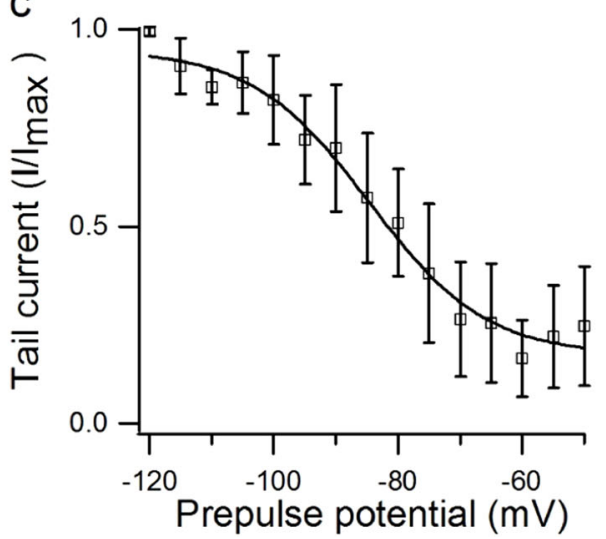

Fig. 5 Effect of veratridine on the tail current of Nav1.7. a Typical traces showing the conditioning prepulse dependence of the effect of veratridine at $75 \mu \mathrm{M}$ on tail currents $(\square)$ of Nav1.7 when excited from a holding potential of $-100 \mathrm{mV}$ to $40 \mathrm{mV}$ for $500 \mathrm{~ms}$ before a step pulse of $-10 \mathrm{mV}$ for $50 \mathrm{~ms}$, followed by a holding potential of $-100 \mathrm{mV}$ for $600 \mathrm{~ms}$. b Statistical data showing the peak of the Nav1.7 tail current in the presence or absence of veratridine as in a $(n=5)$. c Conditioning-prepulse-dependent inactivation curve of the tail current induced by 75 $\mu \mathrm{M}$ veratridine $(n=6)$, which was fitted with the Boltzmann equation, where $V_{1 / 2}=-62 \pm 0.99 \mathrm{mV}, k=5.74 \pm 0.88 \mathrm{mV}$. Paired Student's $t$ test, ${ }^{* *} P<0.01$ vs control

\section{DISCUSSION}

Veratridine has been widely investigated for its activating effect on sodium channels $[12,29,34,35]$. In this study, we have demonstrated that veratridine has a dose-dependent inhibitory effect on Nav1.7 peak current. We have also established that veratridine at a high concentration shifts both the activation and steady-state inactivation curves in the hyperpolarized direction and modulates Nav1.7 current in a use-dependent manner. Veratridine also dose dependently evokes a sustained current and a tail current that contributes to the activation of Nav1.7. As veratridine has been used as a pharmacological tool to activate sodium channels in drug screening and scientific research $[5,36,37]$, and Nav1.7 is an important drug target for the nociceptive system $[25,26]$, our study provides important support for further research on the function of Nav1.7 in sensory systems and for pain-related drug discovery and development.

Veratridine has been reported to depolarize the membrane potential in a manner that scales with the logarithm of its concentration, with only slight depolarization at $10^{-6} \mathrm{~g} / \mathrm{mL}(\sim 1.4$ $\mu \mathrm{M})$ and strong depolarization at $10^{-5} \mathrm{~g} / \mathrm{mL}(\sim 14.8 \mu \mathrm{M})$ or more [38-40]. Here, we studied the responses of the currents to different doses and observed dose-dependent inhibition of the peak current of the sodium channel from 2 to $75 \mu \mathrm{M}$, with an $\mathrm{IC}_{50}$ of $18.39 \mu \mathrm{M}$, and enhancement of the compensatory sustained current $\left(E_{50}: 9.53 \mu \mathrm{M}\right)$ and tail current (30-100 $\left.\mu \mathrm{M}\right)$ (Fig. 1), which could be a possible explanation for the strong membrane response to higher but not lower concentrations of veratridine.
Veratridine at $50-100 \mu \mathrm{M}$ inhibits the peak current of Nav1.4, Nav1.5, Nav1.7, Nav1.2, and Nav1.6 in HEK293 cells to different extents and enhances the sustained inward current and tail current in all of these channels [11,41,42]. Our data confirmed these effects of veratridine on Nav1.7, suggesting that veratridine has a general effect on these three parameters in different subtypes of VGSCs. Veratridine at 5-50 $\mu \mathrm{M}$ inhibits the TTXsensitive and TXX-resistant sodium currents in DRG neurons in a dose-dependent manner [27], while lower doses have been reported to exhibit the opposite effect to higher doses on Nav1.6 in murine vas deferens myocytes: veratridine at 1-10 $\mu \mathrm{M}$ increases the peak amplitude of Nav1.6, while $30-75 \mu \mathrm{M}$ veratridine decreases it [30]. We found that veratridine $(2-75 \mu \mathrm{M})$ exhibited a dose-dependent inhibitory effect on the peak current of Nav1.7 (Fig. 1), which is consistent with its effect on the sodium channels of DRG neurons [27] but not with its effect on Nav1.6 channels in myocytes [30].

Modulation of voltage gating by veratridine $(100 \mu \mathrm{M})$ has been examined in Nav1.2 [43], in which it shifts the activation curve toward hyperpolarization, while for vas deferens myocytes Nav1.6 [30] and N18 neuroblastoma sodium channel [44], there is no shift of the activation curves. In DRG neurons, veratridine $(25 \mu \mathrm{M})$ shifted the activation curves of both TTX-sensitive and TTXresistant current in the hyperpolarized direction [27]. Our data showed that veratridine $(75 \mu \mathrm{M})$ shifted the activation curve in the hyperpolarization direction by about $-6 \mathrm{mV}$ (Fig. 2c), which is similar to the effect of veratridine on Nav1.2 [43] and sodium 

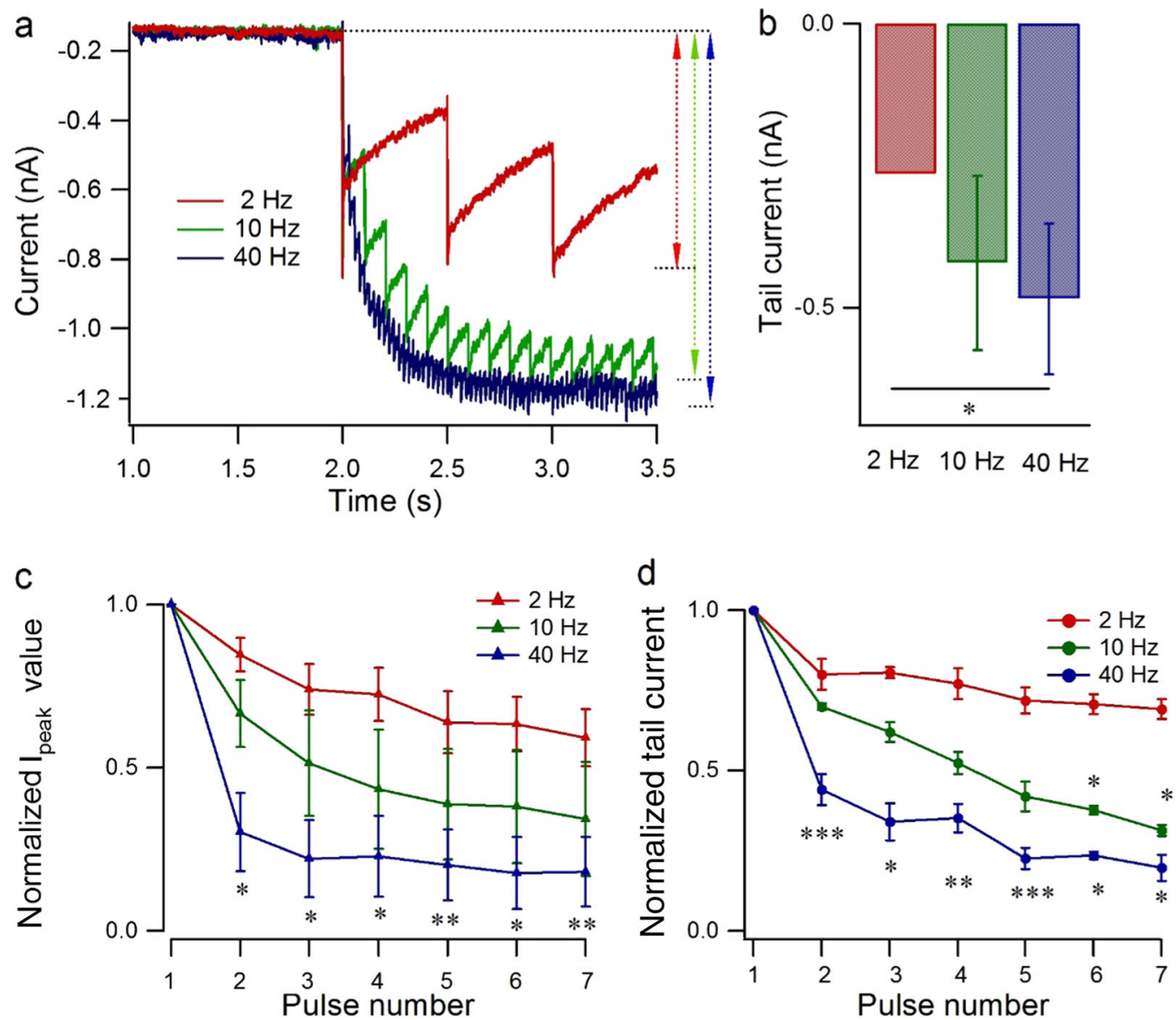

Fig. 6 Use-dependent modulatory effect of veratridine on Nav1.7 peak current and tail current. a Typical traces showing the effect of veratridine $(75 \mu \mathrm{M})$ on Nav1.7 currents, which were activated from a holding potential of -100 to $-10 \mathrm{mV}(5 \mathrm{~ms}$ duration) at $2 \mathrm{~Hz}, 10 \mathrm{~Hz}$, and $40 \mathrm{~Hz}$. b Statistics on the amplitude of the tail current induced by veratridine $(75 \mu \mathrm{M})$, evoked as in a after $10 \mathrm{~s}$ of depolarization at different frequencies $(n=4)$. c, d Statistics on the peak current $(\mathbf{c})$ and tail current $(\mathbf{d})$ for each pulse (both normalized to the value at the first pulse) from pulse 1 to pulse 6 as in a at different frequencies $(n=3)$. Paired Student's $t$ test, ${ }^{*} P<0.05,{ }^{* *} P<0.01,{ }^{* * *} P<0.001 \mathrm{vs} 2 \mathrm{~Hz}$

current in DRG neurons [27] but not its effects on Nav1.6 [30] or N18 neuroblastoma sodium channels [44].

Previous reports show that there is no effect on the inactivation curve of Nav1.6 in myocytes [30], sodium channels in N18 neuroblastoma cells [44], or TX-sensitive sodium channels in DRG neurons [27] in response to veratridine at $100 \mu \mathrm{M}$ or $25 \mu \mathrm{M}$ $[27,30,44]$, while in DRG neurons the inactivation curve of TTXresistant sodium channels shifts toward hyperpolarization in response to veratridine $(25 \mu \mathrm{M})$ [27]. As the TTX-sensitive sodium channels Nav1.1, Nav1.6, and Nav1.7 are expressed in DRG neurons $[19,45]$, the effect of veratridine on Nav1.7 cannot be distinguished from its effect on other TTX-sensitive channels in DRG neurons. In our study, we found that veratridine $(75 \mu \mathrm{M})$ shifted the inactivation curve of Nav1.7 in the hyperpolarized direction (Fig. 3b), which is similar to its effect on DRG TTX-resistant channels [27] but different from its effect on N18 neuroblastoma sodium channels [44] and Nav1.6 [30]. TTX inhibited the peak current of Nav1.7 and shifted the inactivation curve in the hyperpolarized direction as veratridine did (Fig. 2, Figure S5, Fig. 4c), but TTX did not induce any excitatory effects such as enhancement of the sustained current or tail current, and, similar to veratridine, it exhibited little effect on the activation curve of Nav1.7 (Figs. 2 and 3b, Figure S5), which is consistent with the effect of $300 \mathrm{nM}$ TTX on the TTXsensitive sodium current [46]; thus, TTX affects Nav1.7 channels only as a blocker and not as an opener.

Veratridine has been proposed to bind only to open-state sodium channels, as suggested by investigation of the veratridinemodified tail current in skeletal muscle $[12,29]$ and N18 neuroblastoma cells [44]; it has also been proposed to bind to inactivated sodium channels in frog nerve fibers, which showed different recovery rates of peak and tail currents after a train of depolarization [47]. Veratridine inhibits the peak current of the BTX-resistant mutant Nav1.4 sodium channel but fails to induce a sustained current or a tail current, which suggests a two-step binding model for veratridine [48]: an initial binding step, which results in peak current inhibition, and a second step, resulting in trapping of veratridine in the inner vestibule, which overlaps in large part with the local anesthetic receptor $[48,49]$. In the present study, we found that the tail current increased and reached a plateau after prolonged depolarization or high-frequency stimulation, which is consistent with what has been found in muscle skeletal sodium channels [12, 29,44], and each tail current evoked by a single pulse decreased along with the pulse number, suggesting that the open state is needed before the tail current can occur, consistent with the open-state binding model $[12,29,44]$. Regarding the peak current, we found that veratridine shifted the inactivation curve of the peak current in the hyperpolarized direction (Fig. 4), inhibited the peak current more with a prepulse potential of $-60 \mathrm{mV}$ than $-100 \mathrm{mV}$ (Figure S6), and inhibited the peak current to a greater extent with the higher frequency of depolarization (Fig. 6), suggesting that veratridine could also bind to Nav1.7 in the inactivated state to inhibit its peak current. A similar effect has been shown for other $\mathrm{Na}^{+}$blockers such as lidocaine (for Nav1.7) and carvacrol (for the TTX-R sodium current), which are suggested to bind to the inactivated state of the channel [50-52]. 
In conclusion, our study showed that veratridine exhibited a dose-dependent and use-dependent inhibitory effect on the peak current of Nav1.7 and shifted the activation curve and steady-state inactivation curve of Nav1.7 in the hyperpolarized direction, while enhancing the sustained current and tail current, which could contribute to the associated $\mathrm{Na}^{+}$influx. Our study reveals a new mechanism for the modification of Nav1.7 gating by veratridine.

\section{ACKNOWLEDGEMENTS}

This study was sponsored by the National Natural Science Foundation of China (31600950). The hNav1.7 plasmid including the a subunit and the $\beta 1 / \beta 2$ subunits was a generous gift from Dr. Christopher Geoffrey Woods (The Clinical Medical School, University of Cambridge, UK). We appreciate Dr. James Cox's help and guidance with the shipping of this plasmid. We thank Younus Muhammad for providing language help

\section{AUTHOR CONTRIBUTIONS}

$\mathrm{X}$-yZ performed the experiments and wrote the manuscript; PZ prepared the cell line and drug reagents; R-yB contributed to the plasmid preparation; Y-hG designed the research and revised the paper.

\section{ADDITIONAL INFORMATION}

The online version of this article (https://doi.org/10.1038/s41401-018-0065-z) contains supplementary material, which is available to authorized users.

Competing interests: The authors declare no competing interest.

\section{REFERENCES}

1. Wang SY, Wang GK. Voltage-gated sodium channels as primary targets of diverse lipid-soluble neurotoxins. Cell Signal. 2003;15:151-9.

2. Nemoto T, Yanagita T, Maruta T, Sugita C, Satoh S, Kanai T, et al. Endothelin-1induced down-regulation of NaV1.7 expression in adrenal chromaffin cells: attenuation of catecholamine secretion and tau dephosphorylation. FEBS Lett. 2013;587:898-905.

3. Bicknell RJ, Schofield JG. Inhibition by somatostatin of bovine growth hormone secretion following sodium channel activation. J Physiol. 1981;316:85-96.

4. Hill AJ, Jones NA, Smith I, Hill CL, Williams CM, Stephens GJ, et al. Voltage-gated sodium ( $\mathrm{NaV}$ ) channel blockade by plant cannabinoids does not confer anticonvulsant effects per se. Neurosci Lett. 2014;566:269-74.

5. Felix JP, Williams BS, Priest BT, Brochu RM, Dick IE, Warren VA, et al. Functional assay of voltage-gated sodium channels using membrane potential-sensitive dyes. Assay Drug Dev Technol. 2004;2:260-8.

6. Telinius N, Majgaard J, Kim S, Katballe N, Pahle E, Nielsen J, et al. Voltage-gated sodium channels contribute to action potentials and spontaneous contractility in isolated human lymphatic vessels. J Physiol. 2015;593:3109-22.

7. Saleh S, Yeung SY, Prestwich S, Pucovsky V, Greenwood I. Electrophysiological and molecular identification of voltage-gated sodium channels in murine vascular myocytes. J Physiol. 2005;568:155-69.

8. Fort A, Cordaillat M, Thollon C, Salazar G, Mechaly I, Villeneuve N, et al. New insights in the contribution of voltage-gated $\mathrm{Na}(\mathrm{v})$ channels to rat aorta contraction. PLoS One. 2009;4:e7360.

9. Auerbach DS, Grzda KR, Furspan PB, Sato PY, Mironov S, Jalife J. Structural heterogeneity promotes triggered activity, reflection and arrhythmogenesis in cardiomyocyte monolayers. J Physiol. 2011;589:2363-81.

10. Pinto FM, Ravina CG, Fernandez-Sanchez M, Gallardo-Castro M, Cejudo-Roman A, Candenas L. Molecular and functional characterization of voltage-gated sodium channels in human sperm. Reprod Biol Endocrinol. 2009;7:71.

11. Tsukamoto T, Chiba Y, Nakazaki A, Ishikawa $Y$, Nakane $Y, C$ ho $Y$, et al. Inhibition of veratridine-induced delayed inactivation of the voltage-sensitive sodium channel by synthetic analogs of crambescin B. Bioorg Med Chem Lett. 2017;27:1247-51.

12. Sutro JB. Kinetics of veratridine action on Na channels of skeletal muscle. J Gen Physiol. 1986;87:1-24.

13. Catterall WA, Cestele S, Yarov-Yarovoy V, Yu FH, Konoki K, Scheuer T. Voltagegated ion channels and gating modifier toxins. Toxicon. 2007;49:124-41.

14. Janiszewski L. The action of toxins on the voltage-gated sodium channel. Pol J Pharmacol Pharm. 1990;42:581-8.

15. Kanai T, Nemoto T, Yanagita T, Maruta T, Satoh S, Yoshikawa N, et al Nav1.7 sodium channel-induced $\mathrm{Ca} 2+$ influx decreases tau phosphorylation via glycogen synthase kinase-3beta in adrenal chromaffin cells. Neurochem Int. 2009:54:497-505.

16. Richelson E. Lithium ion entry through the sodium channel of cultured mouse neuroblastoma cells: a biochemical study. Science. 1977;196:1001-2.

17. Armstrong CM, Bezanilla F. Inactivation of the sodium channel. II. Gating current experiments. J Gen Physiol. 1977;70:567-90.

18. Khodorov Bl. Inactivation of the sodium gating current. Neuroscience. 1979;4:865-76.

19. Kruger LC, Isom LL. Voltage-gated $\mathrm{Na}+$ channels: not just for conduction. Cold Spring Harb Perspect Biol. 2016;8:a029264

20. Alicata DA, Rayner MD, Starkus JG. Sodium channel activation mechanisms Insights from deuterium oxide substitution. Biophys J. 1990;57:745-58.

21. Kuo CC, Bean BP. Na+ channels must deactivate to recover from inactivation. Neuron. 1994;12:819-29.

22. Black JA, Frezel N, Dib-Hajj SD, Waxman SG. Expression of Nav1.7 in DRG neurons extends from peripheral terminals in the skin to central preterminal branches and terminals in the dorsal horn. Mol Pain. 2012;8:82.

23. Catterall WA. Structure and function of voltage-gated ion channels. Annu Rev Biochem. 1995;64:493-531.

24. Wood JN, Boorman JP, Okuse K, Baker MD. Voltage-gated sodium channels and pain pathways. J Neurobiol. 2004;61:55-71.

25. Dib-Hajj SD, Yang Y, Black JA, Waxman SG. The Na(V)1.7 sodium channel: from molecule to man. Nat Rev Neurosci. 2013;14:49-62.

26. Zhao F, Li X, Jin L, Zhang F, Inoue M, Yu B, et al. Development of a rapid throughput assay for identification of hNav1.7 antagonist using unique efficacious sodium channel agonist, antillatoxin. Mar Drugs. 2016; 14(2): md14020036.

27. Farrag KJ, Bhattacharjee A, Docherty RJ. A comparison of the effects of veratridine on tetrodotoxin-sensitive and tetrodotoxin-resistant sodium channels in isolated rat dorsal root ganglion neurons. Pflugers Arch. 2008;455:929-38.

28. Mohammed ZA, Doran C, Grundy D, Nassar MA. Veratridine produces distinct calcium response profiles in mouse dorsal root ganglia neurons. Sci Rep. 2017;7:45221.

29. Leibowitz MD, Sutro JB, Hille B. Voltage-dependent gating of veratridinemodified Na channels. J Gen Physiol. 1986;87:25-46.

30. Zhu HL, Wassall RD, Takai M, Morinaga H, Nomura M, Cunnane TC, et al. Actions of veratridine on tetrodotoxin-sensitive voltage-gated $\mathrm{Na}$ currents, Na1.6, in murine vas deferens myocytes. Br J Pharmacol. 2009;157:1483-93.

31. Cox JJ, Reimann F, Nicholas AK, Thornton G, Roberts E, Springell K, et al. An SCN9A channelopathy causes congenital inability to experience pain. Nature. 2006;444:894-8.

32. Chai $Z$, Wang $C$, Huang $R$, Wang $Y$, Zhang $X$, Wu $Q$, et al. CaV2.2 gates calciumindependent but voltage-dependent secretion in mammalian sensory. Neurons Neuron. 2017;96:1317-26 e4.

33. Zhang B, Zhang XY, Luo PF, Huang W, Zhu FP, Liu T, et al. Action potentialtriggered somatic exocytosis in mesencephalic trigeminal nucleus neurons in rat brain slices. J Physiol. 2012;590:753-62.

34. Talvenheimo JA, Tamkun MM, Catterall WA. Reconstitution of neurotoxinstimulated sodium transport by the voltage-sensitive sodium channel purified from rat brain. J Biol Chem. 1982;257:11868-71.

35. Tamkun MM, Talvenheimo JA, Catterall WA. The sodium channel from rat brain Reconstitution of neurotoxin-activated ion flux and scorpion toxin binding from purified components. J Biol Chem. 1984;259:1676-88.

36. Bouron A, Reuter $\mathrm{H}$. A role of intracellular $\mathrm{Na}+$ in the regulation of synaptic transmission and turnover of the vesicular pool in cultured hippocampal cells. Neuron. 1996;17:969-78.

37. Catterall WA. Cellular and molecular biology of voltage-gated sodium channels. Physiol Rev. 1992;72:S15-48.

38. Ulbricht W, Flacke W. After-potentials and large depolarizations of single nodes of Ranvier treated with veratridine. J Gen Physiol. 1965;48:1035-46.

39. Ulbricht $W$. The effect of veratridine on excitable membranes of nerve and muscle. Ergeb Physiol. 1969;61:18-71.

40. Sumiya Y, Torigoe K, Gerevich Z, Kofalvi A, Vizi ES. Excessive release of $\left[{ }^{3} \mathrm{H}\right]$ noradrenaline by veratridine and ischemia in spinal cord. Neurochem Int 2001;39:59-63.

41. Bradley E, Webb TI, Hollywood MA, Sergeant GP, McHale NG, Thornbury KD. The cardiac sodium current $\mathrm{Na}(\mathrm{v}) 1.5$ is functionally expressed in rabbit bronchial smooth muscle cells. Am J Physiol Cell Physiol. 2013;305:C427-35.

42. Abdel-Aziz $H$, Windeck $T$, Ploch $M$, Verspohl EJ. Mode of action of gingerols and shogaols on 5-HT3 receptors: binding studies, cation uptake by the receptor channel and contraction of isolated guinea-pig ileum. Eur J Pharmacol. 2006;530:136-43.

43. Power KE, Carlin KP, Fedirchuk B. Modulation of voltage-gated sodium channels hyperpolarizes the voltage threshold for activation in spinal motoneurones. Exp Brain Res. 2012;217:311-22. 
44. Barnes S, Hille B. Veratridine modifies open sodium channels. J Gen Physiol. 1988;91:421-43.

45. Ho C, O'Leary ME. Single-cell analysis of sodium channel expression in dorsal root ganglion neurons. Mol Cell Neurosci. 2011;46:159-66.

46. Liu XP, Wooltorton JR, Gaboyard-Niay S, Yang FC, Lysakowski A, Eatock RA. Sodium channel diversity in the vestibular ganglion: NaV1.5, NaV1.8, and tetrodotoxin-sensitive currents. J Neurophysiol. 2016;115:2536-55.

47. Rando TA. Rapid and slow gating of veratridine-modified sodium channels in frog myelinated nerve. J Gen Physiol. 1989;93:43-65.

48. Wang GK, Quan C, Seaver M, Wang SY. Modification of wild-type and batrachotoxin-resistant muscle mu1 Na+ channels by veratridine. Pflugers Arch. 2000;439:705-13.
49. Wang GK, Wang SY. Veratridine block of rat skeletal muscle Nav1.4 sodium channels in the inner vestibule. J Physiol. 2003;548:667-75.

50. Chevrier $\mathrm{P}$, Vijayaragavan $\mathrm{K}$, Chahine M. Differential modulation of Nav1.7 and Nav1.8 peripheral nerve sodium channels by the local anesthetic lidocaine. $\mathrm{Br} \mathrm{J}$ Pharmacol. 2004;142:576-84.

51. Joca HC, Vieira DC, Vasconcelos AP, Araujo DA, Cruz JS. Carvacrol modulates voltage-gated sodium channels kinetics in dorsal root ganglia. Eur J Pharmacol. 2015;756:22-9.

52. Pal K, Gangopadhyay G. Probing kinetic drug binding mechanism in voltagegated sodium ion channel: open state versus inactive state blockers. Channels (Austin). 2015;9:307-16. 